\title{
Local Protein Synthesis Mediates a Rapid Increase in Dendritic Elongation Factor 1A after Induction of Late Long- Term Potentiation
}

\author{
Panayiotis Tsokas, ${ }^{1}$ Elizabeth A. Grace, ${ }^{1}$ PokMan Chan, ${ }^{2}$ Tao Ma, ${ }^{1}$ Stuart C. Sealfon, ${ }^{1,2,3}$ Ravi Iyengar, ${ }^{1,4}$ \\ Emmanuel M. Landau, ${ }^{1,4,5}$ and Robert D. Blitzer ${ }^{1,4,5}$ \\ Departments of ${ }^{1}$ Pharmacology and Biological Chemistry, ${ }^{2}$ Neurology, ${ }^{3}$ Neuroscience, and ${ }^{4}$ Psychiatry, Mount Sinai School of Medicine, New York, New \\ York 10029, and 5sychiatry Service, Bronx Veterans Affairs Medical Center, Bronx, New York 10468
}

\begin{abstract}
The maintenance of long-term potentiation (LTP) requires a brief period of accelerated protein synthesis soon after synaptic stimulation, suggesting that an early phase of enhanced translation contributes to stable LTP. The mechanism regulating protein synthesis and the location and identities of mRNAs translated are not well understood. Here, we show in acute brain slices that the induction of protein synthesis-dependent hippocampal LTP increases the expression of elongation factor 1A (eEF1A), the mRNA of which contains a $5^{\prime}$ terminal oligopyrimidine tract. This effect is blocked by rapamycin, indicating that the increase in EF1A expression is mediated by the mammalian target of rapamycin (mTOR) pathway. We find that mRNA for eEF1A is present in pyramidal cell dendrites and that the LTP-associated increase in eEF1A expression was intact in dendrites that had been severed from their cell bodies before stimulation. eEF1A levels increased within $5 \mathrm{~min}$ after stimulation in a translation-dependent manner, and this effect remained stable for $3 \mathrm{~h}$. These results suggest a mechanism whereby synaptic stimulation, by signaling through the mTOR pathway, produces an increase in dendritic translational capacity that contributes to LTP maintenance.
\end{abstract}

Key words: hippocampus; LTP; local protein synthesis; mTOR; eEF1A; TOP mRNA

\section{Introduction}

Neuronal stimulation that induces long-term synaptic changes is often associated with increased protein synthesis in dendrites, which are known to contain mRNAs and protein translational machinery (for review, see Martin et al., 2000; Steward and Schuman, 2003). Moreover, protein synthesis is required for the maintenance of persistent forms of synaptic plasticity, including long-term depression (LTD) and long-term potentiation (LTP) (Krug et al., 1984; Otani et al., 1989; Kang and Schuman, 1996; Osten et al., 1996; Huber et al., 2000; Manahan-Vaughan et al., 2000; Sajikumar and Frey, 2003). Currently, neither the mechanisms regulating protein synthesis in dendrites nor the identities of the mRNAs that are translated are fully known.

Recent findings have implicated the mammalian target of rapamycin (mTOR) pathway in LTP maintenance. Specifically, it has been shown that mTOR activity is required for stable LTP (Tang et al., 2002; Cammalleri et al., 2003) and that the mTOR pathway is activated in the dendrites of hippocampal neurons in

\footnotetext{
Received Feb. 14, 2005; revised May 9, 2005; accepted May 11, 2005.

This work was supported by a Veterans Affairs Merit grant to E.M.L. and by National Institutes of Health Grants DA15863 (E.M.L.), GM54508 (R.I.), and DK46943 (S.C.S.). P.T. was a recipient of an Alexander S. Onassis Public Benefit Foundation Award, and E.A.G. was supported by National Institute on Drug Abuse Postdoctoral Training Grant DA017135. We thank Nahum Sonenberg for many enlightening discussions, Maria Grazia Giovannini for technical advice, and Scott Henderson for assistance with confocal microscopy.

Correspondence should be addressed to Robert D. Blitzer, Department of Pharmacology and Biological Chemistry, Mount Sinai School of Medicine, Box 1215, One Gustave L. Levy Place, New York, NY 10029. E-mail: robert.blitzer@mssm.edu.

DOI:10.1523/JNEUROSCI.0599-05.2005

Copyright $\odot 2005$ Society for Neuroscience $\quad$ 0270-6474/05/255833-11\$15.00/0
}

response to LTP-inducing stimulation (Cammalleri et al., 2003). The mTOR pathway controls translation in many systems, in part by regulating the synthesis of new translational machinery (Meyuhas, 2000; Gingras et al., 2001). This process involves the selective translation of mRNAs with terminal oligopyrimidine (TOP) tracts in their 5' untranslated regions (UTRs). Proteins encoded by such transcripts include ribosomal proteins and elongation factors, the synthesis of which may increase the translational capacity of the cell. In many cases, this increase in translational capacity is coordinated with an activation of protein synthesis, primarily at the initiation step.

Because the induction of neuronal plasticity has been shown to activate initiation factors (Kelleher et al., 2004; Takei et al., 2004), we asked whether there could be a corresponding synthesis of a TOP mRNA-encoded translation factor in dendrites after LTP-inducing stimulation. We studied eukaryotic elongation factor $1 \mathrm{~A}(\mathrm{eEF} 1 \mathrm{~A})$, which binds and transports aminoacyl-tRNA to the A site of the ribosome (Merrick and Nyborg, 2000), and found that the transcript for this protein is expressed in dendrites of hippocampal CA1 pyramidal cells. Upon induction of protein synthesis-dependent LTP at the CA3 $\rightarrow$ CA1 synapse, eEF1A expression increased rapidly (within $5 \mathrm{~min}$ ) through a local dendritic mechanism, and this effect was blocked by translation inhibitors. Furthermore, the eEF1A increase was mediated by the mTOR pathway. These findings are consistent with the hypothesis that eEF1A is synthesized in the dendrites from preexisting mRNA. The stimulation-induced expression of a component of the translational machinery may represent a distinct dendritic 
mechanism for the regulation of translation, one that may be required for the extensive synthesis of proteins seen after stimulation that induces stable LTP.

\section{Materials and Methods}

Electrophysiology. Male Sprague Dawley rats (6-8 weeks of age) were deeply anesthetized with halothane and decapitated. The brain was rapidly removed and placed in ice-cold artificial CSF (ACSF) containing the following (in mM): $118 \mathrm{NaCl}, 3.5 \mathrm{KCl}, 1.3 \mathrm{MgSO}_{4}, 3.5 \mathrm{CaCl}_{2}, 1.25$ $\mathrm{NaH}_{2} \mathrm{PO}_{4}, 24 \mathrm{NaHCO}_{3}$, and 15 glucose, bubbled with $95 \% \mathrm{O}_{2} / 5 \% \mathrm{CO}_{2}$. The hippocampus was then rapidly dissected out, and transverse slices of $500 \mu \mathrm{m}$ thickness were made on a tissue chopper at an ambient temperature $4^{\circ} \mathrm{C}$. The slices were maintained in an interface chamber (ACSF and humidified $95 \% \mathrm{O}_{2} / 5 \% \mathrm{CO}_{2}$ atmosphere) at room temperature for at least $2 \mathrm{~h}$ before removal for recording. For recording, the slices were transferred to a submersion chamber preheated to $30-31^{\circ} \mathrm{C}$, in which they were superfused on a nylon mesh with ACSF. Monophasic, constant-current stimuli (100 $\mu$ s) were delivered with a bipolar stainlesssteel electrode (Frederick Haer Company, Bowdoinham, ME) placed in the stratum (s.) radiatum of the CA3 region, and the field EPSP (fEPSP) was recorded in the stratum radiatum of the CA1 region with electrodes filled with $\operatorname{ACSF}\left(R_{\mathrm{e}}=3-5 \mathrm{M} \Omega\right)$. The fEPSP was monitored by delivering stimuli at $0.033 \mathrm{~Hz}$, and the signals were low-pass filtered at $3 \mathrm{kHz}$ and digitized at $20 \mathrm{kHz}$. fEPSPs were acquired, and amplitudes and maximum initial slopes were measured, using either an Axobasic routine or pClamp 9 (Molecular Devices, Union City, CA). We included in our experiments only slices in which the spike threshold was $\geq 2 \mathrm{mV}$. In most experiments, LTP was induced by two $1 \mathrm{~s}$ long trains of $100 \mathrm{~Hz}$ highfrequency stimulation (HFS), separated by $20 \mathrm{~s}$, using a stimulus intensity sufficient to evoke a $1.5 \mathrm{mV}$ fEPSP before HFS. This two-train procedure is referred to as "strong" stimulation, and a similar protocol has been shown to induce protein synthesis-dependent LTP in the CA1 region (Osten et al., 1996). In some experiments, we used "weak" stimulation, consisting of a single $1 \mathrm{~s}$ long $100 \mathrm{~Hz}$ train delivered at an intensity that evoked a baseline fEPSP between 0.6 and $0.75 \mathrm{mV}$. In all experiments, HFS was delivered at least $30 \mathrm{~min}$ after transfer of the slices into the recording chamber, when the basal EPSP had been stable for at least $15 \mathrm{~min}$. Most experiments involving subsequent immunoblotting or immunohistochemistry included sham-stimulated controls placed in the recording chamber and subjected to test stimuli only. In some timecourse experiments, unstimulated controls were placed in the recording chamber concurrently with experimental slices and were harvested at the same time (corresponding to 5, 30, 60, and $120 \mathrm{~min}$ after HFS delivery) as the paired stimulated slices. No significant differences were observed in Western immunoblotting experiments or with immunohistochemistry between these unstimulated and sham-stimulated controls. Data points were normalized to the final $10 \mathrm{~min}$ of the baseline period and are presented as group means \pm SEs. Drug preincubation was performed at room temperature in submersion maintenance chambers containing ACSF saturated with bubbling $95 \% \mathrm{O}_{2} / 5 \% \mathrm{CO}_{2}$. Anisomycin, cycloheximide, emetine, and rapamycin were prepared as stock solutions in dimethylsulfoxide (DMSO), diluted to $0.1 \%$ in ACSF, and applied in the preincubation chamber for $30 \mathrm{~min}$ and in the superfusate throughout the recording period, beginning $30 \mathrm{~min}$ before HFS (i.e., a total of $60 \mathrm{~min}$ before HFS). Controls for these experiments were also preincubated and superfused in 0.1\% DMSO. D-(-)-2-Amino-5-phosphonopentanoic acid (D-APV) was dissolved directly in ACSF and applied in the superfusate for $10 \mathrm{~min}$ before HFS. In some experiments (see Fig. $5 B, C$ ), the somata of CA1 pyramidal neurons were severed from their apical dendrites in the stratum radiatum with a single complete cut, performed with a microdissection knife in the stratum radiatum proximal to the CA1 pyramidal cell body layer (Frey et al., 1989; Kang and Schuman, 1996). The cuts were made at least $2 \mathrm{~h}$ after hippocampal slice preparation, with the slice immobilized in the recording chamber between two nylon meshes and continuously perfused by ACSF at room temperature. The cut slices were allowed to recover at room temperature in the recording chamber for at least 2 additional hours before recording. The completeness of the dissociation of the cell body from the dendrites was electrophysiologically verified by the absence of a positive fEPSP at the pyramidal cell layer when the stimulation electrode was placed in the stratum radiatum in the vicinity of the lesioned section. The stimulus intensity was set to evoke a fEPSP of $0.6 \mathrm{mV}$ during baseline, and HFS was performed using a stimulus that evoked an initial fEPSP of 1.2-1.5 mV.

Western immunoblotting. Slices were removed from the recording chamber and immediately frozen on microscope slides on dry ice. The CA1 region was microdissected in a $4^{\circ} \mathrm{C}$ cold room under a dissection microscope with a glass stage chilled with dry ice. Care was taken to ensure that the tissue remained frozen throughout the procedure. Samples were transferred to cold microcentrifuge tubes and stored at $-80^{\circ} \mathrm{C}$ for not $>3 \mathrm{~d}$ before assaying. A similar dissection method was used in experiments in which stratum radiatum from area CA1 was excised. Each CA1 region was homogenized in $75 \mu \mathrm{l}$ of ice-cold lysis buffer $(30 \mu \mathrm{l}$ for stratum radiatum preparations) using a motorized Potter-Elvehjem homogenizer directly in the microcentrifuge tube (10 strokes, 1 stroke/s). The lysis buffer had the following composition (in mM, unless indicated otherwise): 25 Tris-HCl, pH 7.4, $150 \mathrm{NaCl}, 6 \mathrm{MgCl}_{2}, 2$ EDTA, $26 \mathrm{Na}$ fluoride, 20 DTT, $10 \beta$-glycerophosphate, 4 para-nitrophenylphosphate, $4 \mathrm{Na}$ tartrate dihydrate, $2 \mathrm{Na}$ pyrophosphate, 2 imidazole, $1 \mathrm{Na}$ orthovanadate, $1 \mathrm{Na}$ molybdate, $50 \mu \mathrm{M}(-)$-p-bromotetramisole oxalate, $10 \mu \mathrm{M}$ cantharidin, $1 \mu \mathrm{M}$ okadaic acid, $1 \mu \mathrm{M}$ microcystin-LR, 1 phenylmethylsulfonyl fluoride, $20 \mu \mathrm{g} / \mathrm{ml}$ leupeptin, and $4 \mu \mathrm{g} / \mathrm{ml}$ aprotinin. Protein determination was performed using the Bio-Rad (Hercules, CA) RC-DC protein assay kit. Appropriate volumes of $4 \times$ NuPage LDS sample buffer (Invitrogen, Carlsbad, CA) and $\beta$-mercaptoethanol were added to the homogenates, and samples were boiled for $5 \mathrm{~min}$. Samples (15-20 $\mu$ g of protein per well) were loaded on an $8 \%$ SDS-PAGE gel and resolved by standard electrophoresis. The gels were then transferred electrophoretically onto nitrocellulose membranes (pore size, $0.2 \mu \mathrm{m}$; Invitrogen) using a transfer tank kept at $4^{\circ} \mathrm{C}$. Membranes were blocked for $30 \mathrm{~min}$ at room temperature with blocking buffer [BB; 5\% nonfat dry milk in TBS containing $0.1 \%$ Tween 20 (TBS-T) ] and probed overnight at $4^{\circ} \mathrm{C}$ using primary antibodies for phospho(Thr389)-p70 S6 kinase (p70S6K) (mouse monoclonal; clone 1A5; 1:5000; Cell Signaling Technology, Beverly, MA), eEF1A (mouse monoclonal; clone CBP-KK1; 1:10000; Upstate Biotechnology, Lake Placid, NY), or phospho(Ser2448)-mTOR (rabbit polyclonal; 1:1000; Cell Signaling Technology). All primary antibodies were dissolved in BB. After washing in TBS-T (three washes, 5 min each), the membranes were incubated with horseradish peroxidase-conjugated anti-rabbit or anti-mouse IgG (1:5000; Pierce Biotechnology, Rockford, IL), and proteins were visualized using chemiluminescence (ECL Western blotting analysis system; Amersham Biosciences, Arlington Heights, IL). Membranes were then stripped by strong agitation with $0.2 \mathrm{~N} \mathrm{NaOH}$ ( $15 \mathrm{~min}$, room temperature), blocked in $\mathrm{BB}$ for $30 \mathrm{~min}$ at room temperature, and probed overnight at $4^{\circ} \mathrm{C}$ using an antibody for actin (mouse monoclonal; clone AC40; 1:5000; Sigma, St. Louis, MO). By far, the most intense band in Westerns with the 1A5 monoclonal antibody was phospho(T389)p70S6K, requiring 5-10 s exposure. Films developed for 10 min or longer revealed faint bands for two other phosphorylated(T389)-S6K isoforms, p85S6K and S6K2, which are known to possess nuclear localization signals and are therefore expected to be primarily restricted to the nucleus. Because all three monoclonal antibodies were found to be highly specific and yielded nonoverlapping bands, we applied them concurrently in some experiments. Densitometric analysis of the bands was performed using NIH Image software. Phospho(Thr389)p70S6K, phospho(Ser2448)-mTOR, and eEF1A values were normalized to actin. Data were analyzed using one-tailed and (where specified) twotailed $t$ tests or, where appropriate, ANOVAs followed by Tukey post hoc tests, using Prism (GraphPad Software, San Diego, CA) and Origin (Origin Lab, Northampton, MA). Summary data are presented as group means with SE bars.

Immunohistochemistry. After recording, $500 \mu \mathrm{m}$ slices were placed in ice-cold $4 \%$ paraformaldehyde $/ 0.1 \%$ glutaraldehyde in PBS, pH 7.4, and fixed overnight. After washing, the slices were cut into $40 \mu \mathrm{M}$ sections using a Leica (Bannockburn, IL) VT 1000 S vibratome. Free-floating sections were blocked with $10 \%$ normal goat serum, $1 \% \mathrm{BSA}$, and $0.01 \% \mathrm{Na}$ azide in PBS. The sections then were incubated overnight at $4^{\circ} \mathrm{C}$ with 
primary antibody (if two antibodies were monoclonal and polyclonal, they were incubated together) in 1\% BSA. Fixed tissue sections were probed with the same primary antibodies used for Western immunoblotting: anti-phospho(Thr389)-p70S6K (mouse monoclonal; clone 1A5; 1:250; Cell Signaling Technology) and anti-eEF1A (mouse monoclonal; clone CBP-KK1; 1:250; Upstate Biotechnology). In most experiments, sections were also costained with an anti- $\beta$-tubulin (mouse monoclonal; clone SDL.3D10; 1:500; Sigma) to confirm that all antibodies penetrated to the same extent in all tissue sections and to show neuronal architecture. After washing in PBS, sections were incubated in 1\% BSA with secondary antibodies complexed to either Alexa Fluor 568 or Alexa Fluor 488 (both used at 1:250; Molecular Probes, Eugene, OR). Where multiple monoclonal primary antibodies were used, the slices were washed thoroughly after application of the secondary antibody and sequentially incubated with the next primary antibody. After extensive washing, the sections were mounted and imaged using a Zeiss (Oberkochen, Germany) LSM meta-510 confocal microscope at a scanning depth of $1.9 \mu \mathrm{m}$ $(200 \times)$ or $0.9 \mu \mathrm{m}(400 \times)$. Alexa Fluor 488 immunofluorescence was detected with an ArKr 488/568 laser set at 505-545 nm bandpass emission. The same laser was used with a 560-615 nm long-pass emission filter for the visualization of Alexa Fluor 568. All parameters (pinhole, contrast, and brightness) were held constant for all sections from the same experiment. For double-label experiments, scans at different wavelengths were digitally merged. Multiple overlapping fields within the same focal plane were imaged and were assembled to visualize the entire CA1 region. For the experiments summarized in Figure $6 C$, a semiquantitative method was used to examine the changes in immunoreactivity of eEF1A at different regions along the somatodendritic axis of area CA1. Immunohistochemistry and confocal microscopy were performed as outlined above. Mean immunofluorescence for eEF1A was subsequently measured and analyzed using NIH Image. Regions of interest (ROI) measuring $40 \times 50$ $\mu \mathrm{m}$ were distributed over the stratum pyramidale and stratum radiatum in area CA1 at a distance of $>500 \mu \mathrm{m}$ away from the stimulation site in CA3. The average of 10-15 ROI for each location was determined for four such regions: one in the s. pyramidale and three in the stratum radiatum (proximal, within $100 \mu \mathrm{m}$ of the s. pyramidale; medial, equidistant from the s. pyramidale and s. lacunosum-moleculare; and distal, within 100 $\mu \mathrm{m}$ of the s. lacunosum moleculare). Data were analyzed using onetailed $t$ tests. Summary data are presented as group means with SE bars.

Fluorescent in situ hybridization. Transcardiac perfusion of a male Sprague Dawley rat (350 g) was performed with $10 \mathrm{~mm}$ phosphate buffer (PB), followed by $30 \mathrm{ml}$ of $4 \%$ paraformaldehyde (PFA) in PB at room temperature. The brain was removed, immersion fixed in 4\% PFA in $1 \times$ PBS (10 mm phosphate buffer, $27 \mathrm{~mm} \mathrm{KCl}$, and $137 \mathrm{~mm} \mathrm{NaCl}, \mathrm{pH} 7.4$ ) at $4^{\circ} \mathrm{C}$ for $60 \mathrm{~min}$, and transferred to 10 and $20 \%$ sucrose in $\mathrm{PB}$ at $4^{\circ} \mathrm{C}$ for $2 \mathrm{~h}$ each, followed by $30 \%$ sucrose at $4^{\circ} \mathrm{C}$ for an additional $12 \mathrm{~h}$. The oligonucleotide probes were synthesized as described previously (Chan et al., 2005). Four oligonucleotide probes based on the rat eEF1A mRNA sequence (GenBank accession number NM_175838) were designed for in situ hybridization. The positions of amino-modified nucleotides are indicated in boldface, and the probe position in the mRNA sequence is within parentheses: GGTGGACTTGCCGGAATCTACGTGTCCAATTACGACGATGTTGATGTGAG (92-141); TACCACGCTCACGCTCAGCTTTCAGTTTGTCCAGGACCCAGGCATACTTG (237-86); CCAAAGCTTCCAGCAGCGTGGTGCCACTGGCACTGCCATCTTTGCGGGTG(723-772);TGGTTCAGGATAATCACCTGAGCAGTGAAGCCAGCTGCTTCCATTGGTGG (1072-1121).

The probes were labeled with $200 \mu \mathrm{g}$ of Alexa Fluor succinimidyl esters dye to $10 \mu \mathrm{g}$ of oligonucleotide and purified by ethanol precipitation. The labeled oligonucleotides were purified using size exclusion liquid chromatography, analyzed on a $12 \%$ denaturing polyacrylamide gel, and visualized using a long UV transilluminator. Fractions that contained short fluorescently labeled products were discarded. The fractions containing only $50 \mathrm{bp}$ fluorescently labeled product were pooled, and the concentration of the probes was determined using a microspectrophotometer (Nanodrop Technologies, Rockland, DE). Floating sections (30 $\mu \mathrm{m}$ thick) of the rat brain were prepared on a sliding microtome (Leica) equipped with a freezing stage (Physitemp Instruments, Clifton, NJ). The sections were mounted onto glass slides and dehydrated through graded alcohol $(70,80,90,100 \%)$. Prehybridization was performed at $37^{\circ} \mathrm{C}$ for $1 \mathrm{~h}$ with prehybridization buffer containing $4 \times$ SSC, $50 \%$ formamide, $400 \mathrm{ng} / \mathrm{ml}$ purified bovine serum albumin, 0.1\% Triton X-100, $1 \mathrm{~mm}$ ribonucleoside vanadyl complexes (Sigma), and $1 \mathrm{ng} / \mathrm{ml}$ unlabeled scrambled probe mixture. Prehybridization buffer was then replaced with hybridization buffer containing $400 \mathrm{ng} / \mathrm{ml} \mathrm{BSA,} 4 \times$ SSC, $0.1 \%$ Triton $\mathrm{X}-100,1 \mathrm{~mm}$ ribonucleoside vanadyl complexes, and a mixture of 1 $\mathrm{ng} / \mu \mathrm{l}$ fluorophore-labeled oligonucleotide probe. Hybridization was performed in a moist incubation chamber overnight in a $37^{\circ} \mathrm{C}$ oven. After hybridization, the sections were washed three times for $30 \mathrm{~min}$ with $1 \times \mathrm{SSC}$ at $55^{\circ} \mathrm{C}$ and then at room temperature for $1 \mathrm{~h}$ with gentle agitation. The sections were rinsed once with $0.1 \times \mathrm{SSC}$ for $5 \mathrm{~min}$ and washed with PBSM $\left(1 \times\right.$ PBS with $\left.50 \mathrm{mM} \mathrm{MgCl}_{2}\right)$ for $10 \mathrm{~min}$. Nuclear counterstaining was performed using 4',6-diamidino-2-phenyindole $(0.1 \mathrm{mg} /$ $\mathrm{ml}$ ) in PBSM for $5 \mathrm{~min}$. The slides were rinsed once in $1 \times \mathrm{PBS}$, dried in a $30^{\circ} \mathrm{C}$ oven, and coverslipped using mounting medium consisting of $90 \%$ glycerol and 1\% p-phenylenediamine dihydrochloride in PBS. The fluorescent in situ hybridization (FISH) sections were visualized using a Zeiss LSM510 inverted confocal laser scanning microscope with a $60 \times$ objective. Alexa 568 red fluorescence was excited at $543 \mathrm{~nm}$ and detected with a $570 \mathrm{~nm}$ long-pass filter.

\section{Results}

\section{Synaptic stimulation that induces protein synthesis- dependent LTP activates the mTOR pathway and increases the expression of elongation factor $1 \mathrm{~A}$ in area CA1}

To identify cellular processes that are specifically engaged by stimulation that induces protein synthesis-dependent LTP at the $\mathrm{CA} 3 \rightarrow \mathrm{CA} 1$ synapse, we used two different patterns of HFS. One of these was a two-train HFS procedure, referred to as strong stimulation (see Materials and Methods), which induced an LTP that was stable for at least $2 \mathrm{~h}$ (Fig. $1 \mathrm{~A}$ ). A weak protocol consisting of a single HFS train produced a decremental potentiation that reliably decayed to baseline within $2 \mathrm{~h}$ (Fig. $1 A$ ). The stability of LTP after strong HFS suggested that it included a late phase, which typically requires protein synthesis. To confirm this, we challenged the LTP acquired with the strong HFS protocol with a translation inhibitor. In slices treated with anisomycin (Fig. $1 B$ ), strong HFS produced a decremental potentiation that decayed with a time course similar to that induced by our weak HFS protocol (compare with Fig. $1 A$ ). This indicated that whereas the LTP induced with strong HFS was protein synthesis dependent, the weak protocol recruited only posttranslational mechanisms. Interestingly, the effect of anisomycin was significant by $15-20$ min after HFS (fEPSP in anisomycin-treated slices was $47 \pm 4 \%$ above baseline during this period, compared with $68 \pm 5 \%$ in vehicle controls; $p<0.01)$. Thus, translation-dependent processes contributed to LTP at this relatively early time, consistent with previous findings using a similar LTP-inducing protocol (Osten et al., 1996).

We evaluated the abilities of these two conditioning procedures to activate the mTOR pathway, which mediates the synthesis of proteins encoded by TOP mRNAs and has been implicated in translation-dependent forms of LTP and LTD (Tang et al., 2002; Cammalleri et al., 2003; Hou and Klann, 2004). Activity in the mTOR pathway was monitored by the phosphorylation of mTOR itself at S2448 and the phosphorylation of p70S6K at the mTOR-dependent site T389. In the CA1 regions of slices that had received strong stimulation, both $\mathrm{mTOR}$ and $\mathrm{p} 70 \mathrm{~S} 6 \mathrm{~K}$ were found to be phosphorylated above control values at $30 \mathrm{~min}$ after HFS, whereas weak stimulation did not affect the phosphorylation state of either protein (Fig. 1C). As a functional indicator of activity in the mTOR pathway, we looked for stimulationdependent increases in the expression of an abundant TOP mRNA-encoded protein, eEF1A. Strong HFS increased eEF1A 
immunoreactivity in area CA1 when measured 30 min after HFS, whereas weak stimulation was without effect (Fig. 1C). The ability of strong stimulation to activate the mTOR pathway and to increase eEF1A expression depended on NMDAtype glutamate receptors (NMDARs), because all effects were blocked by D-APV (Fig. 1C), which also prevented the induction of LTP (data not shown). Dependence on NMDARs suggests that the HFSinduced activation of the mTOR pathway is mediated by a rise in postsynaptic $\mathrm{Ca}^{2+}$ (Perkel et al., 1993), an event that is required for LTP at the CA3 $\rightarrow$ CA1 synapse (Lynch et al., 1983).

To determine whether the HFSinduced increase in eEF1A expression also requires de novo synthesis, we performed immunoblots on CA1 homogenates from anisomycin-treated slices. Anisomycin prevented the HFS-induced increase in eEF1A expression (Fig. 1D), although the phosphorylation of p70S6K was intact. Thus, the strong HFS protocol established late LTP and a translation-dependent increase in the expression of eEF1A in the CA1 region. The activation of translation was not general to all mRNAs, because HFS failed to increase the expression of actin, the transcript of which does not include a 5'TOP (Biberman and Meyuhas, 1997) (Figs. 1C,D).

\section{Rapamycin inhibits LTP, as well as the associated increases in p70S6K phosphorylation and eEF1A expression, in a dose-dependent manner}

The activation of the mTOR pathway by our strong HFS protocol suggests that this pathway participates in protein synthesisdependent LTP, as shown previously for LTP induced by widely spaced trains of HFS (Tang et al., 2002; Cammalleri et al., 2003). We tested this possibility by treating slices with the mTOR inhibitor rapamycin before delivering strong HFS (Fig. $2 A)$. After treatment with $1 \mu \mathrm{M}$ rapamycin, HFS produced only a decremental potentiation of the fEPSP that returned to baseline within $2 \mathrm{~h}[1.6 \pm 0.7 \%$ below baseline $(n=7)$ at $2 \mathrm{~h}$ after HFS; $50.5 \pm$ $0.6 \%(n=6)$ above baseline for vehicletreated controls]. Rapamycin $(1 \mu \mathrm{M})$ by itself had little effect on basal synaptic efficiency. This result indicates that the mTOR pathway is required for protein synthesis-dependent LTP but is not involved in the posttranslational processes that underlie the early phase of LTP. At a lower concentration (100 nM), rapamycin partially blocked the maintenance of LTP, with a potentiation of $16.7 \pm 0.8 \%(n=6)$ remaining $2 \mathrm{~h}$ after HFS.

If the HFS-induced expression of eEF1A is mediated by the
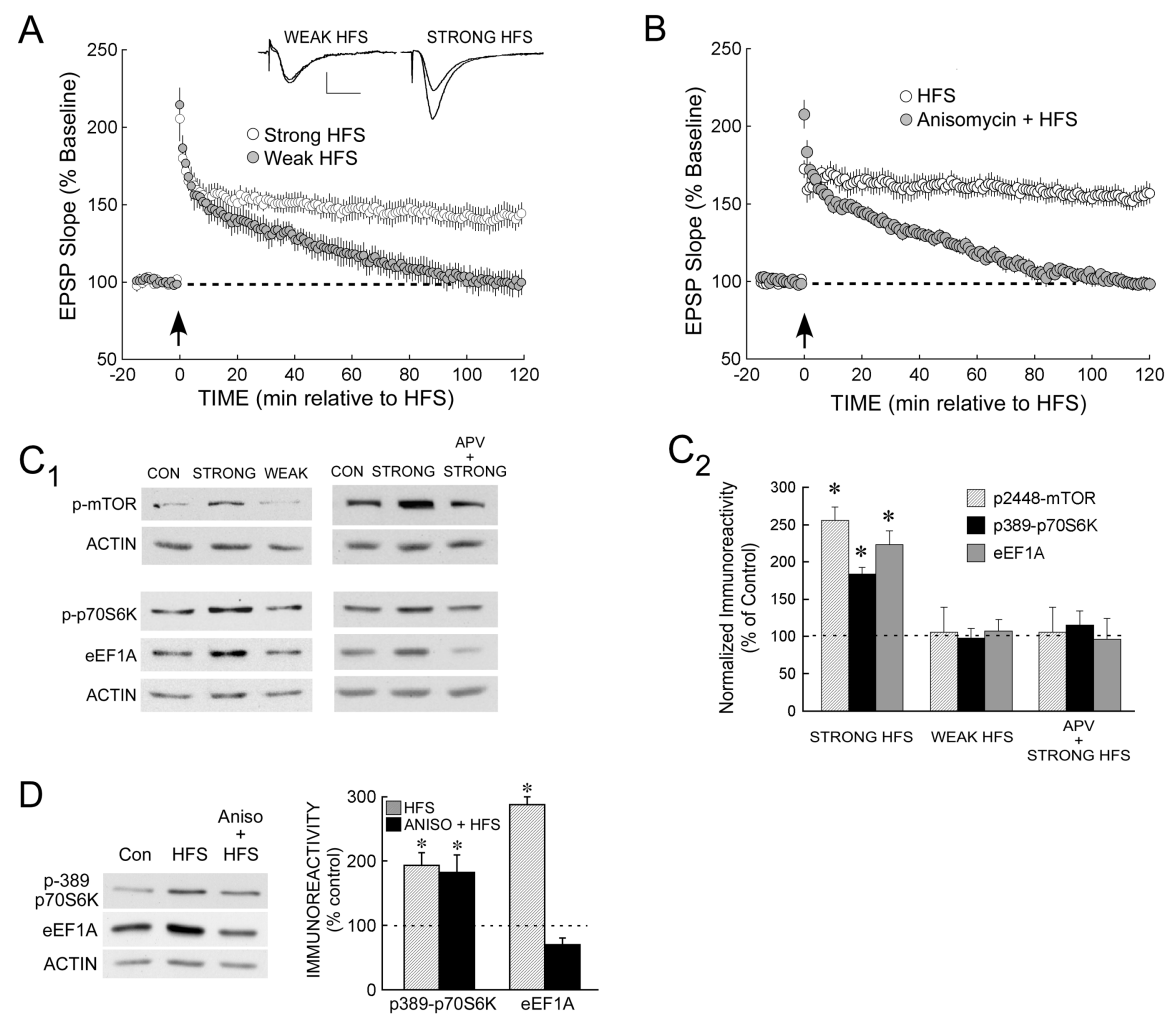

Figure 1. Synaptic stimulation that induces protein synthesis-dependent LTP activates the mTOR pathway and increases eEF1A expression in area CA1.A, Rat hippocampal slices were stimulated, at the time indicated by the arrow, with either two trains of HFS (strong stimulation, as described in Materials and Methods; open symbols; $n=5$ ) or a single train delivered at a lower intensity (weak stimulation; filled symbols; $n=5$ ). Strong HFS produced LTP that persisted for at least $2 \mathrm{~h}$, whereas weak stimulation resulted in only a decremental potentiation that returned to baseline within $2 \mathrm{~h}$. The dashed line represents the normalized baseline value of 100\%. Inset traces show superimposed sample fEPSPs recorded during the baseline period and $2 \mathrm{~h}$ after weak HFS (left traces) or strong HFS (right traces). Calibration: $0.5 \mathrm{mV}, 5 \mathrm{~ms}$. B, In slices treated with $10 \mu$ m anisomycin (filled symbols; $n=7$ ), the synaptic potentiation that followed strong HFS (delivered at arrow) was decremental, returning to baseline within 90 min. In contrast, vehicle-treated controls (open symbols; $n=7$ ) showed LTP that was stable for 2 h. $\boldsymbol{C}$, Strong stimulation, but not weak stimulation, activated the mTOR pathway and increased eEF1A levels in area CA1 in an NMDA receptormediated manner. $\boldsymbol{C}_{1}$, Left, Representative immunoblots from homogenates of CA1 regions from slices that had been frozen 30 min after control stimulation (CON; left lane), strong HFS (center lane), or weak HFS (right lane). Right, Immunoblots from CA1 regions of slices that received either control stimulation (left lane) or strong HFS after preincubation with vehicle (center lane) or $50 \mu$ m D-APV (right lane). Membranes were probed for phospho(Ser2448)-mTOR and actin (top) or for phospho(Thr389)-p70S6K, total eEF1A, and actin (bottom). $C_{2}$, Summary data showing mean immunoreactivity for each protein as determined by densitometry, normalized to control values within the same immunoblot. Strong stimulation increased immunoreactivity for phospho$\operatorname{mTOR}[n=6 ; p<0.001$ vs controls $(n=7)]$, phospho-p70S6K $[n=15 ; p<0.001$ vs controls $(n=15)]$, and eEF1A $[n=10$; $p<0.001$ vs controls $(n=10)$ ], but weak stimulation had no effect on these proteins (all $p$ values $>0.10$; for phospho-mTOR, $n=3$ and control, $n=7$; for phospho-p70S6K, $n=10$ and control, $n=15$; for eEF1A, $n=7$ and control, $n=10$ ). Asterisks indicate significant differences from control, which is represented by the dashed line. Preincubation with D-APV blocked the ability of strong HFS to increase the phosphorylation of mTOR [for APV treated, $n=5 ; p>0.10$ vs controls $(n=7)$ ] and the phosphorylation of $p 7056 \mathrm{~K}$ [for APV treated, $n=6 ; p>0.10$ vs controls $(n=15)$ ], as well as the expression of eEF1A [for APV treated, $n=$ $4 ; p>0.10$ vs controls $(n=10)$ ]. Asterisks indicates significant differences from control. $\boldsymbol{D}$, Anisomycin blocked the ability of strong HFS to increase eEF1A expression. Left, Representative immunoblot of CA1 homogenates taken from slices that had received control stimulation (Con; left lane) or strong HFS after preincubation with either vehicle (center lane) or $10 \mu \mathrm{m}$ anisomycin (Aniso). Slices had been frozen 30 min after stimulation. Right, Summary data showing that the activation by strong HFS of the mTOR pathway in area (A1 was intact in anisomycin (ANISO)-treated slices, as shown by the phosphorylation of p70S6K at T389 (left columns). However, anisomycin completely blocked the HFS-induced increase in EEF1A immunoreactivity (right columns), indicating translation-dependent expression of eEF1A in response to strong HFS [in vehicle-treated slices, phosphop70S6K $(n=3), p<0.05$ vs controls $(n=3)$; eEF1A $(n=3), p<0.01$ vs controls $(n=3)$; in anisomycin-treated slices, phospho-p70S6K $(n=3), p<0.05$ vs controls $(n=3)$; eEF1A $(n=3), p>0.10$ vs controls $(n=3$; two-tailed $t$ test)]. Asterisks indicate significant differences from control. Error bars represent $S E$.

mTOR pathway, as expected for a protein encoded by a TOP mRNA, then it should be blocked in slices treated with rapamycin. Moreover, a role for accelerated TOP mRNA translation in protein synthesis-dependent LTP would require that rapamycin show a potency in blocking the increased eEF1A expression sim- 

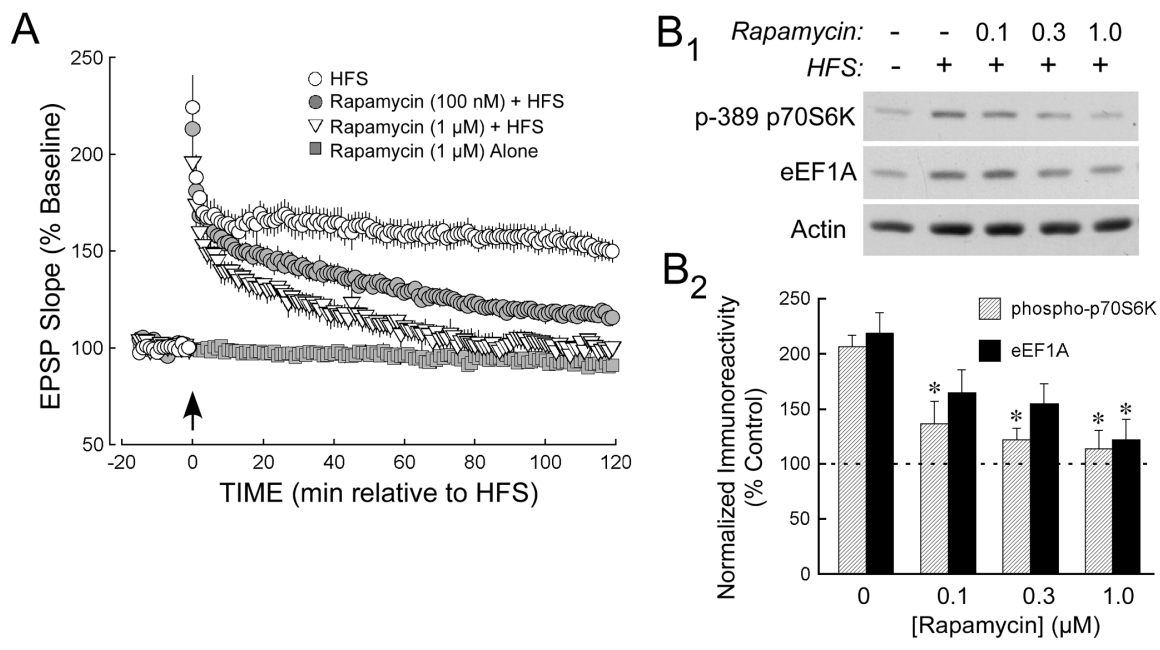

Figure 2. The mTOR pathway is required for stable LTP and for the HFS-induced expression of eEF1A. $A$, Rapamycin blocks the maintenance of LTP induced by strong HFS. In slices pretreated with vehicle (0.5\% DMSO), strong HFS induced stable LTP (open circles; $n=7)$. However, treatment of slices with $100 \mathrm{~nm}$ or $1 \mu \mathrm{m}$ rapamycin [filled circles $(n=6)$ and open triangles $(n=6)$ respectively] produced a dose-dependent block of translation-dependent LTP after HFS (for fEPSP slope measured over the $5 \mathrm{~min}$ period ending $2 \mathrm{~h}$ after HFS and normalized to baseline, vehicle vs $100 \mathrm{~nm}$ rapamycin, $p<0.01$; vehicle vs $1 \mu$ m rapamycin, $p<$ $0.01 ; 100 \mathrm{~nm}$ vs $1 \mu \mathrm{M}$ rapamycin, $p<0.01$ ). Rapamycin had little effect on basal synaptic efficiency, indicating that the mTOR requirement is specific to potentiated synapses. $\boldsymbol{B}$, Rapamycin blocks the increase in eEF1A expression within area CA1 after strong HFS. $\boldsymbol{B}_{\boldsymbol{1}}$, Immunoblots of CA1 homogenates from slices that had received control stimulation in the presence of vehicle (lane 1) strong HFS in the presence of vehicle (lane 2), or different concentrations of rapamycin (lanes 3-5; rapamycin concentration indicated in $\mu \mathrm{M}$ ). HFS increased phospho(T389)-p70S6K and total eEF1A, and rapamycin blocked these effects in a concentrationdependent manner. $\boldsymbol{B}_{\mathbf{2}}$, Summary of rapamycin concentration-response experiments for the blockade of HFS-induced increases in p70S6K phosphorylation (hatched columns) and eEF1A expression (filled columns). The asterisks indicate differences from HFS delivered in the presence of vehicle, and the dashed line indicates the normalized control value. Note that rapamycin was effective in the same concentration range as that used for the inhibition of LTP maintenance. The HFS-induced increase in phospho-p7056K immunoreactivity was significantly reduced (all $p$ values $<0.01)$ by $100 \mathrm{~nm}(n=9), 300 \mathrm{~nm}(n=9)$, and $1 \mu$ m rapamycin $(n=$ $8)$, compared with vehicle-treated slices $(n=9)$; the increase in eEF1A immunoreactivity was significantly inhibited by $1 \mu \mathrm{M}$ rapamycin $(n=6 ; p<0.01)$ but not by $100 \mathrm{~nm}(n=7)$ or $300 \mathrm{~nm}(n=7)$ (for both, $0.10>p>0.05)$. Error bars represent $S E$.

ilar to that for preventing LTP maintenance. We tested the ability of rapamycin $(100 \mathrm{~nm}, 300 \mathrm{nM}$, and $1 \mu \mathrm{M})$ to inhibit the HFSinduced phosphorylation of p70S6K at T389, and the corresponding increase in eEF1A expression, in immunoblots performed on CA1 homogenates from slices taken 30 min after HFS. In agreement with the LTP results, rapamycin at $1 \mu \mathrm{M}$ fully blocked the increase in immunoreactivity both for phosphop70S6K and for total eEF1A, with partial effects at 100 and $300 \mathrm{~nm}$ (Fig. $2 B$ ). These results indicate that the ability of rapamycin to prevent LTP maintenance specifically reflects the inhibition of mTOR and that the HFS-induced expression of eEF1A also depends on activity in the mTOR pathway.

\section{Strong HFS causes extensive phosphorylation of p70S6K and increased expression of eEF1A in dendrites}

To gain insight into the cellular location of translational control in LTP, we used immunohistochemical methods to determine the distribution of mTOR pathway activity and eEF1A expression after strong HFS, using antibodies for phospho(T389)-p70S6K and total eEF1A. In slices stimulated with the strong HFS protocol and fixed 30 min later, immunoreactivity for phosphop70S6K was intensified in well defined dendrites of stratum radiatum relative to slices receiving control stimulation (Fig. 3A). The enhancement in phospho-p70S6K immunoreactivity extended throughout the proximal-distal extent of the dendrites. HFS also increased p70S6K phosphorylation in the cell bodies and diffusely within the stratum oriens.

The HFS-induced expression of eEF1A showed a somatoden- dritic distribution at 30 min that was similar to that of phospho-p70S6K (Fig. 3B). After strong HFS, intense eEF1A immunoreactivity was evident in many dendrites within the stratum radiatum compared with slices that had received control stimulation, and this effect included proximal and distal dendritic regions. A less prominent increase was observed in the cell bodies, in which there was substantial eEF1A immunoreactivity even in control slices. To confirm that HFS-induced dendritic eEF1A expression reflected activity in the mTOR pathway, we challenged the effect with $300 \mathrm{~nm}$ rapamycin. In agreement with our immunoblot data, rapamycin blocked the somatodendritic increases in phospho-p70S6K and eEF1A immunoreactivity after strong HFS (Fig. 3C). These results indicate that the induction of protein synthesis-dependent LTP is associated with the activation of the mTOR pathway in stimulated dendrites and with an increase in the expression of eEF1A that can be detected throughout the dendritic arbor within $30 \mathrm{~min}$.

\section{The mTOR pathway is rapidly stimulated by strong HFS and leads to a persistent increase in eEF1A expression} Because rapamycin specifically interferes with the late phase of LTP, activity in the mTOR pathway must contribute a plasticity-related signal that persists for hours after conditioning stimulation. When applied after HFS, rapamycin does not affect late LTP (Cammalleri et al., 2003); thus, the persistent signal is probably not mTOR itself, but rather some downstream component. We studied the time courses for the phosphorylation of mTOR (at S2448) and p70S6K (at T389), and the increase in eEF1A expression, for $3 \mathrm{~h}$ after HFS (Fig. 4). Because our strong HFS protocol consisted of two closely spaced trains, we were able to resolve early time points in the activation of the mTOR pathway. Immunoreactivities for phospho-mTOR and phospho-p70S6K were significantly increased within 5 min after HFS, indicating a rapid activation of the mTOR pathway. Interestingly, elevated eEF1A expression could also be detected at this early time (Fig. $4 A_{2}, B$ ). At later time points, mTOR became progressively dephosphorylated at S2448 and returned to control levels within $1 \mathrm{~h}$ (Fig. $4 \mathrm{~B}$, left). The phosphorylation of p70S6K at T389 was more stable, remaining elevated for at least $1 \mathrm{~h}$ after HFS (Fig. $4 B$, middle). Finally, the HFS-induced increase in eEF1A levels peaked at 30 min after stimulation and thereafter remained stable for at least $3 \mathrm{~h}$ (Fig. $4 \mathrm{~B}$, right). These data confirm that the contribution of mTOR to late LTP is transient, with more persistent downstream signals provided by phosphorylated p70S6K and by eEF1A. The transient nature of mTOR phosphorylation rules out a contribution of mTOR itself to the maintenance of late LTP.

\section{Local mechanisms are sufficient for HFS-induced increase in dendritic eEF1A}

The anisomycin- and rapamycin-sensitive increase in eEF1A expression in the dendrites is consistent with the hypothesis that 

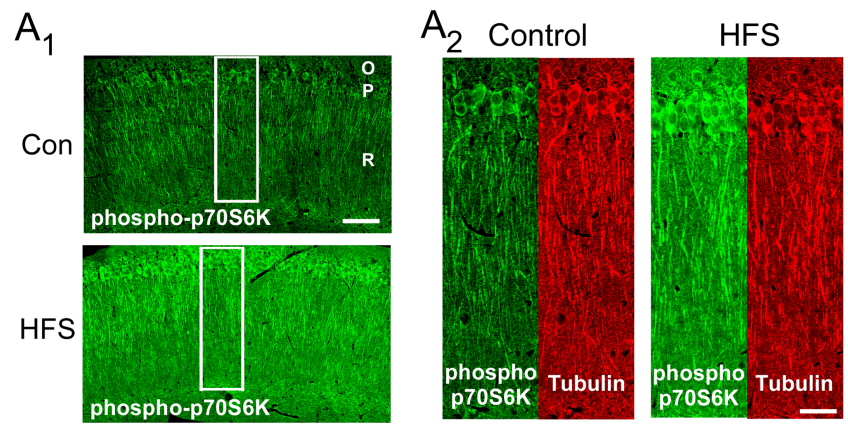

$B_{1}$
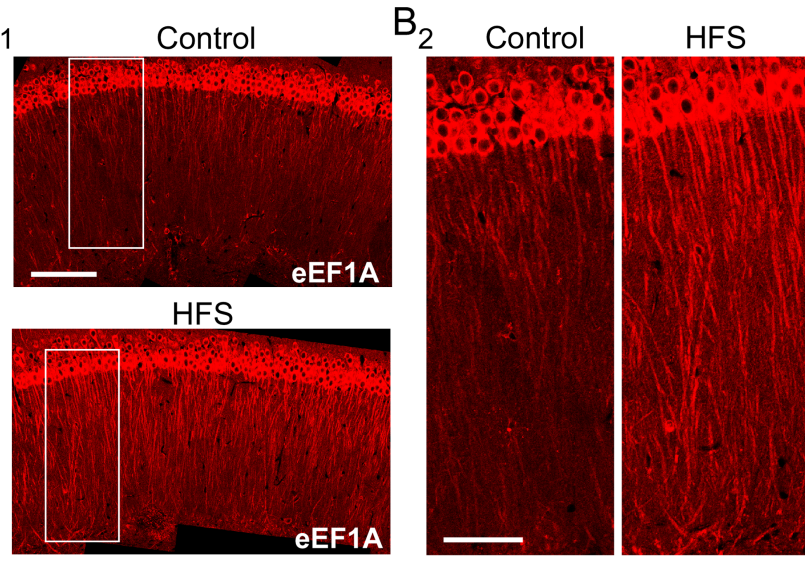

C
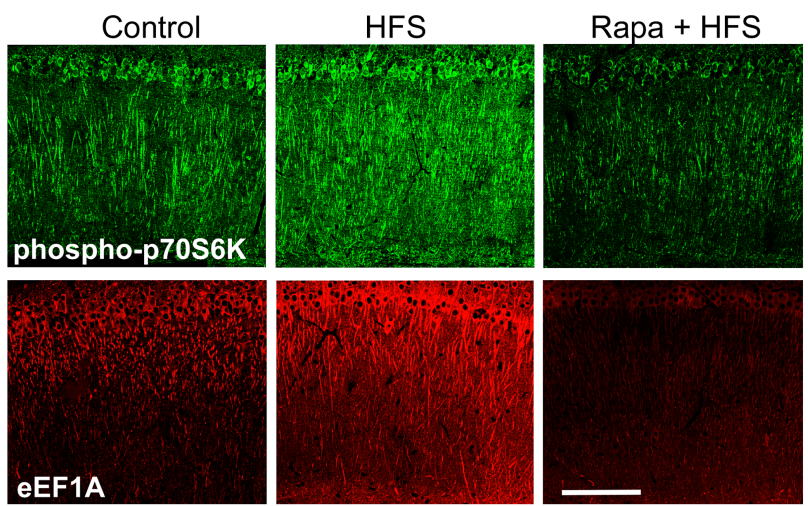

Figure 3. Strong HFS increases eEF1A expression in dendrites. $\boldsymbol{A}$, Slices received either control stimulation or strong HFS and were fixed 30 min later, sectioned, and labeled with antibodies for phospho(T389)-S6K. $\boldsymbol{A}_{\boldsymbol{1}}$, HFS increased immunoreactivity throughout the dendrites of the stratum radiatum $(R)$, in the nuclei and cell bodies of the stratum pyramidale $(P)$, and within the stratum oriens $(0)$. These and all subsequent immunohistochemical images are oriented with area CA3 toward the left. Scale bar, $100 \mu \mathrm{m}$. Con, Control. $\boldsymbol{A}_{2}$, Expanded regions of control and HFS-treated sections corresponding to the rectangles in $\boldsymbol{A}_{1}$, showing immunoreactivity for phospho(T389)-S6K (green) and tubulin (red). Tubulin immunoreactivity was not increased by HFS. These results are representative of $>10$ experiments. Scale bar, $50 \mu \mathrm{m}$. $\boldsymbol{B}$, eEF1A immunoreactivity in sections from slices that had received control stimulation (top image) or strong HFS (bottom image) 30 min before fixation. $\boldsymbol{B}_{\boldsymbol{1}}$, Immunoreactivity for eEF1A was markedly stronger in the dendrites of the stratum radiatum after HFS, with smaller effects in the stratum pyramidale and stratum oriens. Scale bar, $200 \mu \mathrm{m}$. $\boldsymbol{B}_{\mathbf{2}}$, Expansion of areas indicated by the rectangles in $\boldsymbol{B}_{\boldsymbol{1}}$. Within individual dendrites of the stratum radiatum in the HFS-treated slice, eEF1A immunoreactivity was relatively intense and nearly uniform from proximal to distal regions. These results are representative of $>10$ experiments. Scale bar, $100 \mu \mathrm{m}$. C, Rapamycin (Rapa) prevents the increase in dendritic eEF1A expression after strong HFS. Immunohistochemical analysis was performed on sections using antibodies for phospho(T389)-S6K (top) and eEF1A (bottom). Within the dendrites of the stratum radiatum, HFS increased immunoreactivity for phospho-S6K and for total eEF1A compared with slices that had received control stimulation (left and middle panels; vehicle only). The effects were blocked by $300 \mathrm{~nm}$ rapamycin (right panels). Results are representative of eight experiments for phospho-S6K and 12 experiments for eEF1A. Scale bar, $200 \mu \mathrm{m}$.
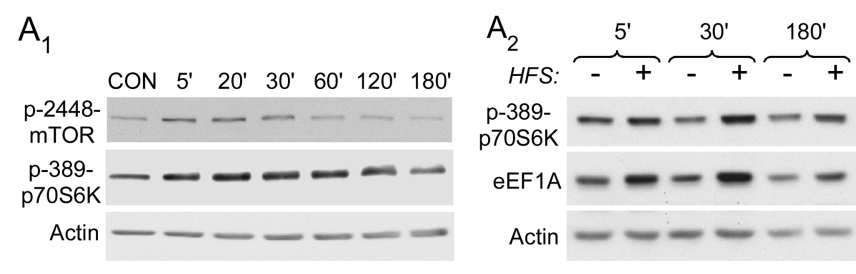

B

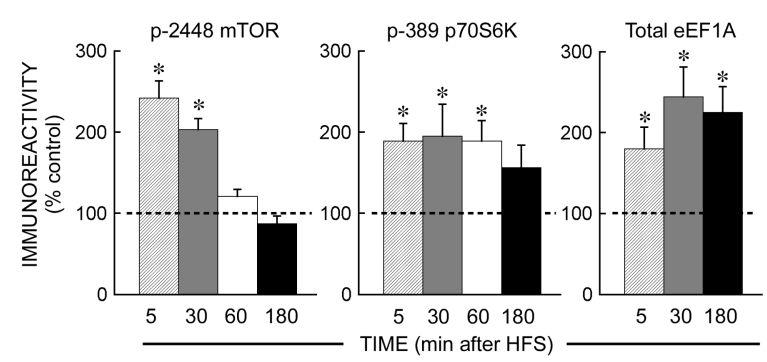

Figure 4. The HFS-induced increase in eEF1A expression is rapid and sustained in area CA1. $\boldsymbol{A}$, Representative immunoblots for the time course of mTOR pathway activation and eEF1A expression after strong HFS. $\boldsymbol{A}_{\boldsymbol{1}}$, An immunoblot of CA1 homogenates from slices that had received either control stimulation for 90 min before slice freezing (CON) or HFS 5-180 min before freezing. Immunoreactivity for phospho(S2448)-mTOR showed a maximal increase at 5-20 min, followed by a decline to control levels within $1 \mathrm{~h}$. Phospho(T389)-p70S6K peaked somewhat later and remained elevated for $\sim 2$ h. $\boldsymbol{A}_{2}$, Immunoblot of CA1 homogenates from time-matched control slices and HFS-treated slices. HFS caused eEF1A expression to increase as early as $5 \mathrm{~min}$ after stimulation, an effect that was maintained for $3 \mathrm{~h}$. The phosphorylation of p7056K showed a similar time course. $B$, Summary of time-course experiments for the HFSinduced activation of the mTOR pathway and expression of eEF1A. The phosphorylation of mTOR (left) and p70S6K (middle) and the increase in eEF1A expression (right) were all significantly increased 5 min after HFS. However, mTOR phosphorylation was relatively brief, and the increase in eEF1A relatively stable. For phospho-mTOR, at $5 \mathrm{~min}, n=3, p<0.05$; at $30 \mathrm{~min}$, $n=3, p<0.01$; at $60 \mathrm{~min}, n=3, p>0.05$; at $180 \mathrm{~min}, n=3, p>0.10$, with all values compared with controls $(n=5)$. For phospho-p7056K, at $5 \mathrm{~min}, n=7, p<0.01$; at $30 \mathrm{~min}$, $n=5, p<0.05$; at 60 min, $n=3, p<0.05$; at $180 \mathrm{~min}, n=3,0.10>p>0.05$, with all values compared with controls $(n=9)$. For eEF1A, at $5 \mathrm{~min}, n=5 ; p<0.05$; at $30 \mathrm{~min}, n=$ $4, p<0.05$; at $180 \mathrm{~min}, n=3, p<0.05$, with all values compared with controls $(n=6)$. The dashed line represents the normalized control value, and the asterisks indicate significant differences from control. Error bars represent SE.

HFS induces the local synthesis of eEF1A. Such an effect could result from a combination of processes, including (1) transcription followed by somatic translation and export of the protein to the dendrites, (2) transport of eEF1A mRNA to the dendrites, where it is then locally translated, and (3) increased rate of translation of preexisting dendritic eEF1A mRNA. To help differentiate among these three mechanisms, we looked for evidence of eEF1A mRNA in the dendrites of unstimulated rat hippocampus. In FISH experiments performed on hippocampal slices obtained from perfusion-fixed rat brains, we detected eEF1A mRNA within the dendrites of stratum radiatum in area $\mathrm{CA} 1$ and in the cell bodies (Fig. 5A). The identification of eEF1A mRNA as a dendritically expressed transcript is in agreement with the findings of Eberwine et al. (2001) and suggests that eEF1A may be synthesized in dendrites from resident mRNA in response to stimulation that establishes protein synthesis-dependent LTP.

To test this hypothesis, we examined hippocampal slices whose CA1 somata had been severed from their apical dendrites in the stratum radiatum with a single complete cut (see Materials and Methods). Previous studies conducted in such slices by Frey et al. (1989) and by Kang and Schuman (1996) have shown that anisomycin-sensitive LTP, measured up to $3 \mathrm{~h}$ after induction, is independent of protein and mRNA transport from the soma. We found that the delivery of HFS to slices with severed dendrites 
A
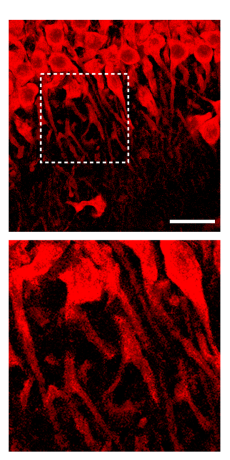

$\mathrm{B}$

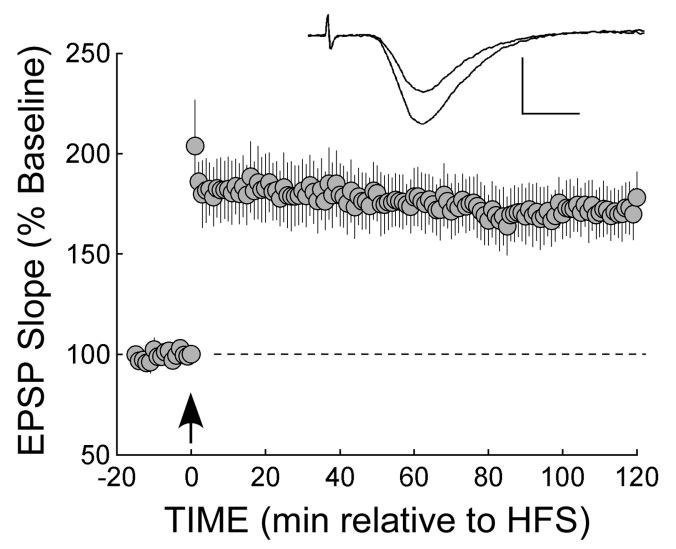

C
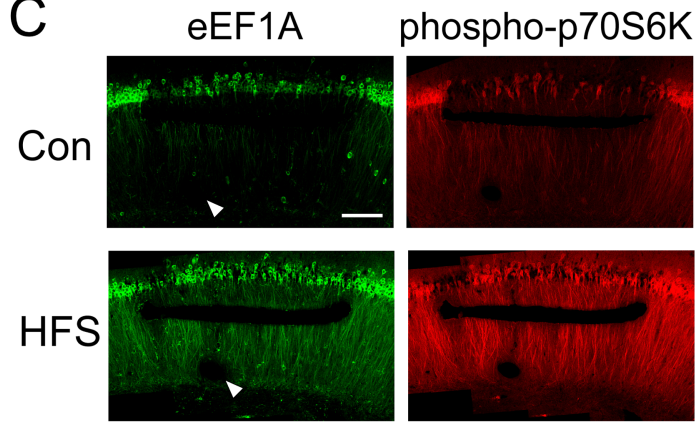

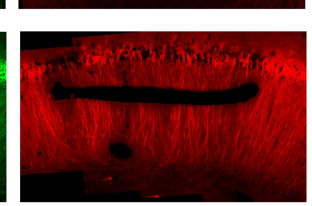

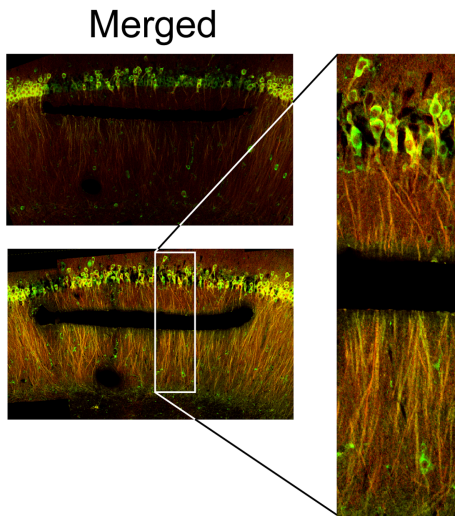

Figure 5. Local mechanisms are sufficient for the HFS-induced increase in dendritic eEF1A.A, FISH with oligonucleotide probes based on the mRNA sequence for rat eEF1A. In sections prepared from perfusion-fixed rat brain, mRNA for eEF1A was detected in area $\mathrm{CA} 1$ within the cell bodies of the stratum pyramidale (top image) and in the dendrites of the stratum radiatum (top image and detail in bottom image). Control FISH experiments using fluorescently labeled scrambled probe or labeled eEF1A probe in the presence of excess unlabeled eEF1A probe gave no detectable signal above background when imaged at the same exposure (data not shown) (Chan et al., 2005). These control studies demonstrate that the labeling observed in neuronal processes is specific for eEF1A sequence. Scale bar, $50 \mu \mathrm{m}$. B, LTP was recorded in the CA1 stratum radiatum of slices in which a cut separated the apical dendrites from the cell bodies proximal to the recording electrode. Strong HFS delivered $2 \mathrm{~h}$ after the cut had been made (see Materials and Methods) produced a stable LTP that was maintained for $2 \mathrm{~h}(n=5)$. The inset traces show superimposed fEPSPs recorded during the baseline period and $2 \mathrm{~h}$ after HFS. Calibration: $1 \mathrm{mV}, 5 \mathrm{~ms}$. C, The HFS-induced increase in eEF1A expression was intact in dendrites separated from their cell bodies. Immunohistochemical analysis was performed on slices in which cuts had been made in the stratum radiatum before control stimulation (Con; top images) or two-train HFS (bottom images). The slices were fixed $1 \mathrm{~h}$ after stimulation. The HFS-induced increases in the phosphorylation of $56 \mathrm{~K}$ at T389 (middle panels), and, more importantly, the expression of eEF1A (left panels) in the separated dendrites were similar to those obtained in the adjacent intact dendrites. Merged images of phospho-S6K and eEF1A immunofluorescence (right panels and expanded image) show a high degree of colocalization for the active mTOR pathway and the expression of eEF1A within the separated dendrites. These images are representative of three experiments for phospho-S6K and four experiments for eEF1A. The arrowhead indicates the placement of the recording electrode. Scale bar, $150 \mu \mathrm{m}$.

resulted in LTP that was stable for at least $2 \mathrm{~h}$ in the isolated region [ $\mathrm{fEPSP}=60.7 \pm 1.2 \%$ above baseline $(n=5)$; measured $2 \mathrm{~h}$ after stimulation] (Fig. 5B). This result corroborates the findings of other groups showing that protein synthesis-dependent LTP is independent of somatic mechanisms for at least $2 \mathrm{~h}$.

We tested whether the isolated dendrites retained the ability to increase eEF1A expression after strong HFS. Severed-dendrite slices that had received either control stimulation or strong HFS were fixed $1 \mathrm{~h}$ later and double-labeled using antibodies for eEF1A and phospho(389)-p70S6K. The complete dissociation of stratum radiatum from stratum pyramidale was confirmed by immunostaining with anti-tubulin antibodies (data not shown) and by electrophysiological criteria (see Materials and Methods). A representative experiment is shown in Figure $5 C$. Severing the dendrites from the soma had little or no effect on dendritic eEF1A expression in control slices, although there was a decline in eEF1A within the pyramidal cell bodies of the isolated region (Fig. $5 C$, left, top image). This loss of somatic expression probably did not reflect gross damage, because tubulin immunoreactivity did not show the same pervasive disruption (data not shown). In response to strong HFS, all stimulated slices showed a robust increase in dendritic labeling for eEF1A in the isolated section of stratum radiatum (Fig. 5C, left, bottom image). Note that the intense immunoreactivity for eEF1A in the isolated region was indistinguishable from that in the neighboring intact region. Given that no mRNA trafficking between cell body and dendrites could have occurred in the lesioned area during the $3.5 \mathrm{~h}$ that elapsed between making the incision and fixing the slice (see Materials and Methods), the HFS-induced expression of eEF1A in isolated dendrites suggests a slow rate of eEF1A mRNA degradation. eEF1A expression also increased in the cell bodies within the isolated region, presumably as a result of synaptic activation by Schaffer collaterals projecting to apical dendrites within the narrow region proximal to the cut or by those that crossed over to stratum oriens within area CA3. These results support the hypothesis that the elevated eEF1A expression after HFS reflects local protein synthesis in the dendrites themselves, from preexisting mRNA.

Within the isolated dendrites, phospho-p70S6K immunoreactivity also increased reliably in response to HFS (Fig. $5 C$, middle). The expression of phosphop70S6K was highly colocalized with that of eEF1A in the dendrites of the stimulated slices (Fig. 5C, right panels), consistent with other data showing that the mTOR pathway mediates the translation of TOP mRNAs.

\section{Dendritic eEF1A expression rises rapidly after strong $\mathrm{HFS}$}

The rise in eEF1A levels within 5 min after stimulation that was observed in western blots (Figs. 4, 6D) indicates that eEF1A may participate in the initial cellular events that establish protein synthesis-dependent LTP. To determine whether this rapid effect occurs in the dendrites, we first performed immunoblots on homogenates of stratum radiatum that had been excised from slices frozen 5 min after strong HFS. If eEF1A is synthesized rapidly within the dendrites after stimulation, it should be possible to detect increased immunoreactivity in this dendrite-enriched tissue at such an early time point. The excision was conservative, sacrificing some proximal stratum radiatum in the interest of avoiding contamination from cell bodies. Tissue taken from stimulated slices showed an increase in eEF1A immunoreactivity that was more pronounced than that obtained in immunoblots of complete CA1 regions. Thus, the average increase in eEF1A im- 
munoreactivity in excised stratum radiatum was $216.0 \pm 52.5 \%$ above controls, compared with $79.5 \pm 26.8$ and $83.5 \pm$ $26.3 \%$ at the same time for whole CA1 regions (Figs. $4 B, 6 D$, respectively), indicating that the increased expression of eEF1A in area CA1 measured 5 min after HFS was primarily contributed by the dendrites rather than the cell bodies.

This suggestion of a rapid increase in dendritic eEF1A was supported by subsequent immunohistochemical experiments performed on slices fixed $5 \mathrm{~min}$ after strong stimulation and labeled for eEF1A (Fig. 6B). Throughout stratum radiatum, including the most distal processes located 400-500 $\mu \mathrm{m}$ from the cell bodies, HFS caused an increase in dendritic eEF1A immunoreactivity. The somatodendritic distribution of this effect was analyzed by measuring average immunofluorescence in the stratum pyramidale and in proximal, medial, and distal regions of stratum radiatum within area CA1. All measures showed increased eEF1A immunoreactivity relative to slices that had received control stimulation (Fig. 6C), with the most pronounced effect seen in the most distal location. These data are incompatible with a somatic origin for the dendritic eEF1A expressed in response to HFS (see Discussion) and lend support to a purely dendritic mechanism for eEF1A synthesis in the period immediately after stimulation that induces protein synthesis-dependent LTP.

A latency of $5 \mathrm{~min}$ for detecting an increase in eEF1A expression is consistent with the eukaryotic rate of synthesis as determined for a number of proteins, which are synthesized at three to eight amino acids per second per ribosome (Mathews et al., 2000). Moreover, TOP mRNAs become fully loaded in polysomes after activation of the mTOR pathway (see Discussion). Thus, if eEF1A mRNA is translated after HFS, a relatively rapid increase in the expression of eEF1A would be expected. To confirm that the rise in eEF1A as early as 5 min after HFS was mediated by de novo protein synthesis, we challenged the increase with several translation inhibitors. Slices were stimulated with strong HFS after preincubation with anisomycin, emetine, cycloheximide, or vehicle and frozen 5 min later. As measured by Western blots of excised CA1 regions, all inhibitors blocked the effect of stimulation on eEF1A immunoreactivity (Fig. 6D), indicating that protein synthesis immediately after HFS is required for the increase in eEF1A expression.

\section{Discussion}

The experiments reported here show that a pathway used during the cell cycle to regulate the rate of translation, the mTORmediated synthesis of translational machinery, is also activated in dendrites by stimulation that induces protein synthesisdependent LTP. In proliferating cells, this mechanism is thought
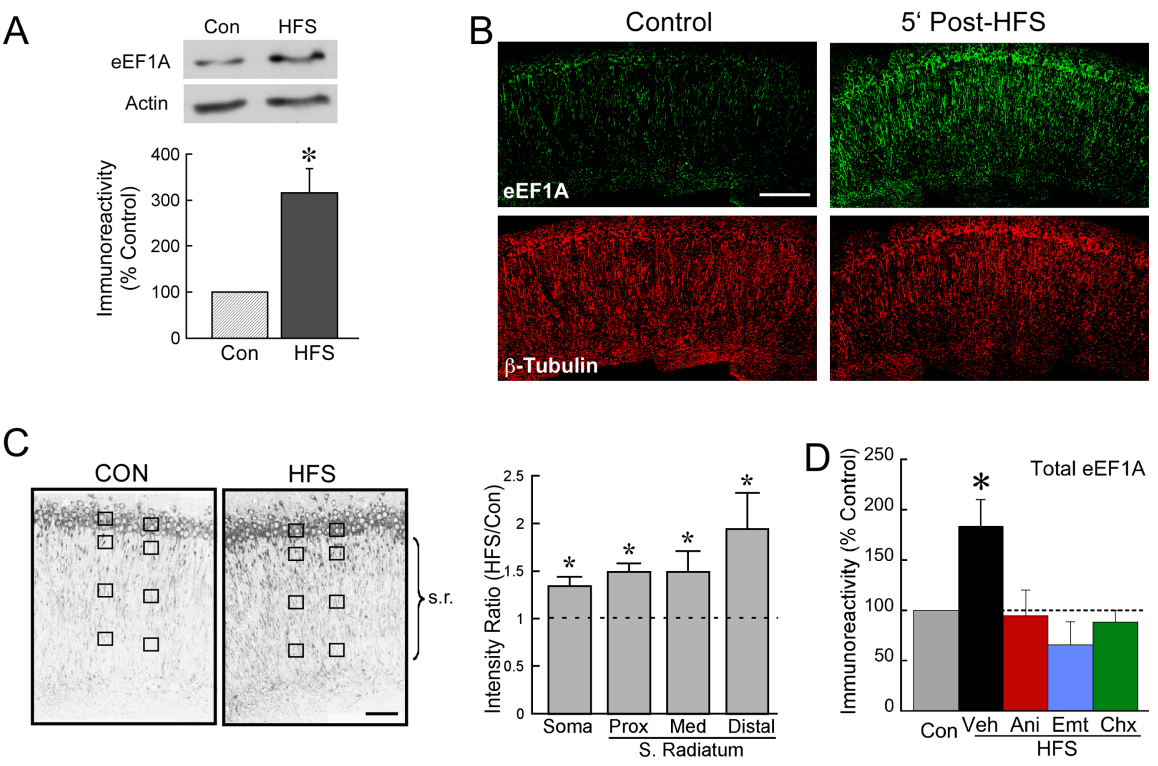

Figure 6. Dendritic eEF1A increases rapidly and in a protein synthesis-dependent manner in response to stimulation that 列 endritic arbor, strong HFS rapidly increases immunoreactivity for eEF1A. Sections from slices fixed 5 min after HFS (right panels) a labeled with antibodies for eEF1A (green) and $\beta$-tubulin (red) showed enhanced dendritic eEF1A immunoreactivity, even in either control stimulation or strong HFS, followed by fixation 5 min later. The sections were labeled with antibodies against eEF1A, the intensity of fluorescence was determined within defined areas evenly distributed along the stratum pyramidale and

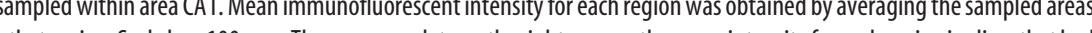
received strong HFS, normalized to the corresponding region in time-matched control slices. Mean immunofluorescence was increased within the stratum pyramidale and in all regions of the stratum radiatum, indicating that eEF1A expression increased in the most distal dendrites in concert with the increase in more proximal (Prox) regions, including the cell bodies. The dashed line increased immunofluorescence in the somatic $(n=3 ; p<0.05)$, proximal dendritic $(n=3 ; p<0.01)$, medial (Med) dendritic ; $p<0.05)$, and distal dendritic regions $(n=3 ; p<0.01)$. $D$, Protein synthesis is required for the HFS-induced increase in

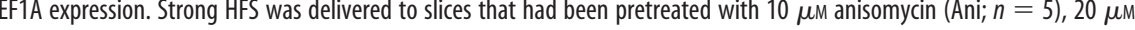
metine (Emt; $n=3), 60 \mu$ m cycloheximide $(C h x ; n=3)$, or $0.1 \%$ DMSO (Veh; $n=7)$ and frozen 5 min later. Excised CA1 regions All three translation inhibitors prevented the increase in eEF1A immunoreactivity; the asterisk indicates significant difference $(p<0.05)$ from control value. Con, Control. Error bars represent SE.

to generate additional translational capacity, thereby accommodating the high rate of protein synthesis associated with periods of growth (Raught et al., 2000). The increased demand for synthetic machinery is triggered by the activation of translation factors through phosphorylation or GDP/GTP exchange, facilitating the formation of the $43 \mathrm{~S}$ preinitiation complex and the recruitment of the ribosome to mRNA (Hershey and Merrick, 2000; Sonenberg and Dever, 2003).

Interestingly, coordinated translation control mechanisms, similar to those implicated in the process of cell growth, appear to operate in the dendrites of neurons that have received LTPinducing stimulation. Thus, within minutes after stimulation, initiation factors are phosphorylated in the dendrites of cultured hippocampal neurons after BDNF treatment and within area CA1 of hippocampal slices after the delivery of HFS (Kelleher et 
al., 2004; Takei et al., 2004). These observations are consistent with the rapid increase in eEF1A protein reported here. In dendrites, the demand for translational capacity may be particularly acute in the minutes immediately after LTP-inducing stimulation, which is a period of increased protein turnover during which protein synthesis and degradation are activated. After HFS, the translational machinery in hippocampal neurons is activated within $10 \mathrm{~min}$, and ${ }^{35} \mathrm{~S}$-methionine is incorporated into many proteins within $30 \mathrm{~min}$ (Kelleher et al., 2004). Similarly, increased protein synthesis can be seen within $10 \mathrm{~min}$ of BDNF application to cultured neurons (Schratt et al., 2004), and the activation of NMDA receptors in synaptosomes results in the synthesis of $\alpha$-calcium/calmodulin-dependent protein kinase II within $3 \mathrm{~min}$ (Scheetz et al., 2000). Furthermore, several studies have shown that protein degradation is increased immediately after neuronal stimulation (Vanderklish et al., 1995, 2000; Ehlers, 2003). These findings are consistent with studies showing that LTP is vulnerable to translation inhibitors for only a relatively short time after the conditioning stimulus (within 15-35 min after stimulation) (Otani et al., 1989; Frey and Morris, 1997; Cammalleri et al., 2003). Thus, it is likely that an early period of increased protein turnover is critical for establishing late LTP. However, little is known about the particular proteins affected and their roles in LTP maintenance. Our experiments show a rapid increase in the expression of eEF1A within dendrites of hippocampal neurons, in response to stimulation that induces protein synthesisdependent LTP. This upregulation occurs within 5 min after stimulation, consistent with a role for the synthesis of eEF1A, and perhaps other components of the translation machinery, in the early cellular events that lead to late LTP.

The synthesis of translational machinery is mediated by the selective translation of TOP mRNAs (Kaspar et al., 1990; Meyuhas, 2000). These transcripts feature relatively short 5' UTRs with little predicted structure (Davuluri et al., 2000), which contain stretches of 4-14 pyrimidines (Levy et al., 1991; Meyuhas, 2000). In resting cells, the TOP mRNAs are excluded from the polysomal fraction (residing within messenger ribonucleoprotein particles or the monosome/disome pool) and are not translated efficiently. When cells are stimulated to grow, the rate of translation for TOP mRNAs increases threefold to fourfold (Aloni et al., 1992), accompanied by a shift of the TOP mRNAs to the polysomal fraction (Jefferies et al., 1997). The transition to the polysomal fraction is not gradual, but rather all-or-none, indicating that TOP mRNA translation is regulated by a specific and as yet unidentified repressor, rather than by the availability of active initiation factors (Meyuhas, 2000).

Stimulation of the mTOR pathway preferentially upregulates TOP mRNA translation, and in many cell types, the mTOR inhibitor rapamycin prevents the shift of TOP mRNAs to the polysomal pool (Jefferies et al., 1997; Pende et al., 2004) (but see Stolovich et al., 2002). In agreement, our results indicate that the increased dendritic expression of eEF1A in response to HFS depends on activity in the mTOR pathway. The potency of rapamycin in preventing the stimulation-dependent activation of mTOR, measured as the phosphorylation of p70S6K at T389, agreed well with the decrease in eEF1A expression. For both measures, rapamycin produced partial inhibition at $100-$ $300 \mathrm{nM}$ and nearly complete blockade at $1 \mu \mathrm{M}$. Furthermore, rapamycin was found to prevent LTP maintenance within the same concentration range. Note that these concentrations were higher than those used to block mTOR in cell cultures, presumably because of diffusional barriers presented by tissue slices.
It is clear that protein synthesis-dependent LTP does not require a persistent mTOR signal. After stimulation, the phosphorylation of mTOR and p70S6K and the increase in eEF1A proceeded with different time courses. All three measures were upregulated within $5 \mathrm{~min}$ after stimulation, but the only stable effect was the change in eEF1A expression, which lasted for at least $3 \mathrm{~h}$. The phosphorylation of mTOR returned to baseline within $1 \mathrm{~h}$, so the long-lived increase in eEF1A does not depend on a prolonged activation of signaling pathways that control mTOR. The transient activation of the mTOR pathway, together with the ineffectiveness of rapamycin when applied after the induction of protein synthesis-dependent LTP (Cammalleri et al., 2003), indicates that mTOR activity is important in the critical period during which LTP is vulnerable to inhibitors of protein synthesis. During this period, the mTOR-dependent synthesis of a specific set of proteins encoded by TOP mRNAs may produce a local and long-lasting reconfiguration of the postsynaptic network responsible for late LTP. In view of the large number of transcripts detected in pyramidal dendrites (Eberwine et al., 2001), it is likely that dendrites contain other TOP mRNAs in addition to that for eEF1A, and the identification of such mRNAs will be an important step toward characterizing dendritic protein synthesis in LTP.

Our findings indicate that local translation of preexisting dendritic mRNA is responsible for the HFS-induced increase in eEF1A and that this effect requires mTOR activity. mRNA for eEF1A is present in the dendrites of pyramidal neurons, and HFS was found to increase eEF1A protein in dendrites separated from their cell bodies (Fig. 5). Thus, stimulation-induced expression of dendritic eEF1A does not require transport of protein or RNA from the cell bodies, consistent with the increase in eEF1A within the distal dendrites 5 min after stimulation (Fig. 6). Although these results establish that local synthesis is sufficient to account for the increase in dendritic eEF1A, they do not rule out the possibility that protein or mRNA trafficking contributes to the particular enrichment observed in distal dendrites after HFS. In distal dendrites, microtubules are predominantly oriented in the same direction (plus ends distal to the cell body), whereas the microtubules of more proximal dendrites have mixed orientations (Baas et al., 1988). RNA granules associate with the heavy chain of kinesin (Mallardo et al., 2003), a motor whose plusdirected movement could preferentially direct granule-bound mRNAs and proteins (including eEF1A) toward distal dendrites. In this context, it is interesting to note that cytoskeletal effects of eEF1A, independent of its role as an elongation factor, may play a role in regulating protein synthesis and in synaptic plasticity. Thus, eEF1A has been shown to bring mRNA and the cytoskeleton into contact (Liu et al., 2002), which is a prerequisite for efficient translation (Stapulionis et al., 1997). Moreover, through its actin bundling and by microtubule-severing activities (Shiina et al., 1994; Liu et al., 2002), eEF1A could influence RNA trafficking within the dendrite (Köhrmann et al., 1999; Tiruchinapalli et al., 2003) and alter spine morphology, which has been implicated in synaptic plasticity (Munshi et al., 2001; Toni et al., 2001). Given the rapidity and stability of its increase after HFS and the possibility of redistribution with time, dendritic eEF1A may play distinct roles in different phases of LTP.

A role for regulated eEF1A expression has also been shown in the long-term facilitation (LTF) of the Aplysia sensory-motor synapse (Giustetto et al., 2003). In response to LTF-inducing stimulation, eEF1A mRNA is transcribed by the sensory neuron and transported into the axon, accompanied by increases in somatic and axonal eEF1A immunoreactivity. However, in Aplysia 
the increase in eEF1A expression is a relatively slow, transcription-dependent process. Also in contrast to the present findings, LTF in Aplysia caused a relatively modest increase in the processes compared with the cell body, and a local mechanism for the increase in eEF1A within the processes has not been shown. The combined hippocampal and Aplysia data indicate that the increased expression of eEF1A, and perhaps other TOP mRNAencoded proteins, may participate in divergent forms of protein synthesis-dependent synaptic plasticity across the phylogenetic spectrum. Such an involvement is consistent with the general concept that the translation of TOP mRNAs enables cells, as well as subcellular compartments such as dendrites, to accommodate a dynamic requirement for increased protein synthesis in response to stimulation.

\section{References}

Aloni R, Peleg D, Meyuhas O (1992) Selective translational control and nonspecific posttranscriptional regulation of ribosomal protein gene expression during development and regeneration of rat liver. Mol Cell Biol 12:2203-2212.

Baas PW, Deitch JS, Black MM, Banker GA (1988) Polarity orientation of microtubules in hippocampal neurons: uniformity in the axon and nonuniformity in the dendrite. Proc Natl Acad Sci USA 85:8335-8339.

Biberman Y, Meyuhas O (1997) Substitution of just five nucleotides at and around the transcription start site of rat $\beta$-actin promoter is sufficient to render the resulting transcript a subject for translational control. FEBS Lett 405:333-336.

Cammalleri M, Lutjens R, Berton F, King AR, Simpson C, Francesconi W, Sanna PP (2003) Time-restricted role for dendritic activation of the mTOR-p70S6K pathway in the induction of late-phase long-term potentiation in the CA1. Proc Natl Acad Sci USA 100:14368-14373.

Chan P, Gonzalez-Maeso J, Ruf F, Bishop DF, Hof PR, Sealfon SC (2005) Epsilon sarcoglycan immunoreactiviy and mRNA expression in mouse brain. J Comp Neurol 482:50-73.

Davuluri RV, Suzuki Y, Sugano S, Zhang MQ (2000) CART classification of human 5' UTR sequences. Genome Res 10:1807-1816.

Eberwine J, Miyashiro K, Kacharmina JE, Job C (2001) Local translation of classes of mRNAs that are targeted to neuronal dendrites. Proc Natl Acad Sci USA 98:7080-7085.

Ehlers MD (2003) Activity level controls postsynaptic composition and signaling via the ubiquitin-proteasome system. Nat Neurosci 6:231-242.

Frey U, Morris RG (1997) Synaptic tagging and long-term potentiation. Nature 385:533-536.

Frey U, Krug M, Brodemann R, Reymann K, Matthies H (1989) Long-term potentiation induced in dendrites separated from rat's CA1 pyramidal somata does not establish a late phase. Neurosci Lett 97:135-139.

Gingras AC, Raught B, Sonenberg N (2001) Regulation of translation initiation by FRAP/mTOR. Genes Dev 15:807-826.

Giustetto M, Hegde AN, Si K, Casadio A, Inokuchi K, Pei W, Kandel ER, Schwartz JH (2003) Axonal transport of eukaryotic translation elongation factor 1alpha mRNA couples transcription in the nucleus to longterm facilitation at the synapse. Proc Natl Acad Sci USA 100: $13680-13685$.

Hershey JWB, Merrick WC (2000) The pathway and mechanism of initiation of protein synthesis. In: Translational control of gene expression (Sonenberg N, Hershey JWB, Mathews MB, eds), pp 33-88. Cold Spring Harbor, NY: Cold Spring Harbor Laboratory.

Hou L, Klann E (2004) Activation of the phosphoinositide 3-kinase-Aktmammalian target of rapamycin signaling pathway is required for metabotropic glutamate receptor-dependent long-term depression. J Neurosci 24:6352-6361.

Huber KM, Kayser MS, Bear MF (2000) Role for rapid dendritic protein synthesis in hippocampal mGluR-dependent long-term depression. Science 288:1254-1257.

Jefferies HB, Fumagalli S, Dennis PB, Reinhard C, Pearson RB, Thomas G (1997) Rapamycin suppresses 5'TOP mRNA translation through inhibition of p70 ${ }^{\text {s6k. }}$. EMBO J 16:3693-3704.

Kang H, Schuman EM (1996) A requirement for local protein synthesis in neurotrophin-induced hippocampal synaptic plasticity. Science 273:1402-1406.
Kaspar RL, Rychlik W, White MW, Rhoads RE, Morris DR (1990) Simultaneous cytoplasmic redistribution of ribosomal protein L32 mRNA and phosphorylation of eukaryotic initiation factor $4 \mathrm{E}$ after mitogenic stimulation of Swiss 3T3 cells. J Biol Chem 265:3619-3622.

Kelleher III RJ, Govindarajan A, Jung HY, Kang H, Tonegawa S (2004) Translational control by MAPK signaling in long-term synaptic plasticity and memory. Cell 116:467-479.

Köhrmann M, Luo M, Kaether C, DesGroseillers L, Dotti CG, Kiebler MA (1999) Microtubule-dependent recruitment of Staufen-green fluorescent protein into large RNA-containing granules and subsequent dendritic transport in living hippocampal neurons. Mol Biol Cell 10:2945-2953.

Krug M, Lossner B, Ott T (1984) Anisomycin blocks the late phase of longterm potentiation in the dentate gyrus of freely moving rats. Brain Res Bull 13:39-42.

Levy S, Avni D, Hariharan N, Perry RP, Meyuhas O (1991) Oligopyrimidine tract at the $5^{\prime}$ end of mammalian ribosomal protein mRNAs is required for their translational control. Proc Natl Acad Sci USA 88:3319-3323.

Liu G, Grant WM, Persky D, Latham Jr VM, Singer RH, Condeelis J (2002) Interactions of elongation factor $1 \alpha$ with $\mathrm{F}$-actin and $\beta$-actin mRNA: implications for anchoring mRNA in cell protrusions. Mol Biol Cell 13:579-592.

Lynch G, Larson J, Kelso S, Barrionuevo G, Schottler F (1983) Intracellular injections of EGTA block induction of hippocampal long-term potentiation. Nature 305:719-721.

Mallardo M, Deitinghoff A, Muller J, Goetze B, Macchi P, Peters C, Kiebler MA (2003) Isolation and characterization of Staufen-containing ribonucleoprotein particles from rat brain. Proc Natl Acad Sci USA 100:2100-2105.

Manahan-Vaughan D, Kulla A, Frey JU (2000) Requirement of translation but not transcription for the maintenance of long-term depression in the CA1 region of freely moving rats. J Neurosci 20:8572-8576.

Martin KC, Barad M, Kandel ER (2000) Local protein synthesis and its role in synapse-specific plasticity. Curr Opin Neurobiol 10:587-592.

Mathews MB, Sonenberg N, Hershey JWB (2000) Origins and principles of translation control. In: Translational control of gene expression (Sonenberg N, Hershey JWB, Mathews MB, eds), pp 1-31. Cold Spring Harbor, NY: Cold Spring Harbor Laboratory.

Merrick WC, Nyborg J (2000) The protein biosynthesis elongation cycle. In: Translational control of gene expression (Sonenberg N, Hershey JW, Mathews MB, eds), pp 89-125. Cold Spring Harbor, NY: Cold Spring Harbor Laboratory.

Meyuhas O (2000) Synthesis of the translational apparatus is regulated at the translational level. Eur J Biochem 267:6321-6330.

Munshi R, Kandl KA, Carr-Schmid A, Whitacre JL, Adams AE, Kinzy TG (2001) Overexpression of translation elongation factor 1A affects the organization and function of the actin cytoskeleton in yeast. Genetics 157:1425-1436.

Osten P, Valsamis L, Harris A, Sacktor TC (1996) Protein synthesisdependent formation of protein kinase $\mathrm{M} \zeta$ in long-term potentiation. J Neurosci 16:2444-2451.

Otani S, Marshall CJ, Tate WP, Goddard GV, Abraham WC (1989) Maintenance of long-term potentiation in rat dentate gyrus requires protein synthesis but not messenger RNA synthesis immediately posttetanization. Neuroscience 28:519-526.

Pende M, Um SH, Mieulet V, Sticker M, Goss VL, Mestan J, Mueller M, Fumagalli S, Kozma SC, Thomas G (2004) S6K1(-/-)/S6K2(-/-) mice exhibit perinatal lethality and rapamycin-sensitive 5 '-terminal oligopyrimidine mRNA translation and reveal a mitogen-activated protein kinase-dependent S6 kinase pathway. Mol Cell Biol 24:3112-3124.

Perkel DJ, Petrozzino JJ, Nicoll RA, Connor JA (1993) The role of $\mathrm{Ca}^{2+}$ entry via synaptically activated NMDA receptors in the induction of longterm potentiation. Neuron 11:817-823.

Raught B, Gingras AC, Sonenberg N (2000) Regulation of ribosomal recruitment in eukaryotes. In: Translational control of gene expression (Sonenberg N, Hershey JW, Mathews MB, eds), pp 245-293. Cold Spring Harbor, NY: Cold Spring Harbor Laboratory.

Sajikumar S, Frey JU (2003) Anisomycin inhibits the late maintenance of long-term depression in rat hippocampal slices in vitro. Neurosci Lett 338:147-150.

Scheetz AJ, Nairn AC, Constantine-Paton M (2000) NMDA receptor- 
mediated control of protein synthesis at developing synapses. Nat Neurosci 3:211-216.

Schratt GM, Nigh EA, Chen WG, Hu L, Greenberg ME (2004) BDNF regulates the translation of a select group of mRNAs by a mammalian target of rapamycin-phosphatidylinositol 3-kinase-dependent pathway during neuronal development. J Neurosci 24:9366-9377.

Shiina N, Gotoh Y, Kubomura N, Iwamatsu A, Nishida E (1994) Microtubule severing by elongation factor $1 \alpha$. Science 266:282-285.

Sonenberg N, Dever TE (2003) Eukaryotic translation initiation factors and regulators. Curr Opin Struct Biol 13:56-63.

Stapulionis R, Kolli S, Deutscher MP (1997) Efficient mammalian protein synthesis requires an intact F-actin system. J Biol Chem 272:24980-24986.

Steward O, Schuman EM (2003) Compartmentalized synthesis and degradation of proteins in neurons. Neuron 40:347-359.

Stolovich M, Tang H, Hornstein E, Levy G, Cohen R, Bae SS, Birnbaum MJ, Meyuhas O (2002) Transduction of growth or mitogenic signals into translational activation of TOP mRNAs is fully reliant on the phosphatidylinositol 3-kinase-mediated pathway but requires neither S6K1 nor rpS6 phosphorylation. Mol Cell Biol 22:8101-8113.

Takei N, Inamura N, Kawamura M, Namba H, Hara K, Yonezawa K, Nawa H
(2004) Brain-derived neurotrophic factor induces mammalian target of rapamycin-dependent local activation of translation machinery and protein synthesis in neuronal dendrites. J Neurosci 24:9760-9769.

Tang SJ, Reis G, Kang H, Gingras AC, Sonenberg N, Schuman EM (2002) A rapamycin-sensitive signaling pathway contributes to long-term synaptic plasticity in the hippocampus. Proc Natl Acad Sci USA 99:467-472.

Tiruchinapalli DM, Oleynikov Y, Kelic S, Shenoy SM, Hartley A, Stanton PK, Singer RH, Bassell GJ (2003) Activity-dependent trafficking and dynamic localization of zipcode binding protein 1 and $\beta$-actin mRNA in dendrites and spines of hippocampal neurons. J Neurosci 23:3251-3261.

Toni N, Buchs PA, Nikonenko I, Povilaitite P, Parisi L, Muller D (2001) Remodeling of synaptic membranes after induction of long-term potentiation. J Neurosci 21:6245-6251.

Vanderklish P, Saido TC, Gall C, Arai A, Lynch G (1995) Proteolysis of spectrin by calpain accompanies theta-burst stimulation in cultured hippocampal slices. Brain Res Mol Brain Res 32:25-35.

Vanderklish PW, Krushel LA, Holst BH, Gally JA, Crossin KL, Edelman GM (2000) Marking synaptic activity in dendritic spines with a calpain substrate exhibiting fluorescence resonance energy transfer. Proc Natl Acad Sci USA 97:2253-2258. 